This is a self-archived version of an original article. This version may differ from the original in pagination and typographic details.

Author(s): Aarnikoivu, Melina

Title: The spatiotemporal dimension of doctoral education : a way forward

Year: 2021

Version: Accepted version (Final draft)

Copyright: (c) 2020 Society for Research into Higher Education

Rights: In Copyright

Rights url: http://rightsstatements.org/page/lnC/1.0/?language=en

Please cite the original version:

Aarnikoivu, M. (2021). The spatiotemporal dimension of doctoral education : a way forward.

Studies in Higher Education, 46(11), 2431-2443.

https://doi.org/10.1080/03075079.2020.1723530 


\section{The spatiotemporal dimension of doctoral education: a way forward}

Author information:

Aarnikoivu, Melina, melina.aarnikoivu@jyu.fi

Centre for Applied Language Studies, University of Jyväskylä, Jyväskylä, Finland

ORCID: https://orcid.org/0000-0003-4626-5840

Twitter:@MAarnikoivu

LinkedIn: https://www.linkedin.com/in/maarnikoivu/

Melina Aarnikoivu is a doctoral researcher at the Centre for Applied Language Studies, University of Jyväskylä, Finland. Her dissertation (in progress) is a nexus analysis of doctoral education, with a special focus on its spatiotemporal dimension, early-career mobility, and academic writing. She is also one of the two lead editors of the ECHER blog (echer.org), an online platform for early-career researchers to share information, experience, and opinion about the interdisciplinary field of higher education research. 


\section{The spatiotemporal dimension of doctoral education: a way forward}

For an individual doctoral student, doctoral education happens in multiple spaces across a considerable amount of time. However, the existing literature and conceptualisations of doctoral education do not adequately address the spatiotemporal dimension related to it. By using the concept of scales, this article examines how the social action of doing doctoral studies is affected by space and time. As a mode of inquiry, I use nexus analysis, which allows the analyst to spotlight issues that routinely go unnoticed by scholars, policy-makers but also doctoral students themselves. Based on the analysis, I argue that to theorise doctoral education further, its spatiotemporal dimension has to be examined more closely and considered more seriously than is currently being done by higher education scholars.

Keywords: doctoral education; nexus analysis; scales; social action; space; time

\section{Introduction}

There are as many ways to do doctoral studies as there are doctoral students. The highly varied demography of today's doctoral students has made doctoral education along with its expanding modes an extremely complex phenomenon, to which no one-size-fits-all approach can be applied. Today, it is possible to complete a doctorate either full-time or part-time (see Gardner and Gopaul 2012). It can be done within one university, including or not including mobility, as distance-learning (see Koole and Stack 2016; Nasiri and Mafakheri 2015), or as a combination of all these. Despite myriad options and increasing flexibility, doctoral students' future prospects are also increasingly insecure (see Hakala 2009; Waaijer et al. 2017), making doctorate a less appealing investment in the future than it might have once been. In 
addition to the versatility of the main actors of this academic drama, doctoral studies involve a multitude of different actions, settings, tools, artefacts, rules, roles, motives, and relationships, all adding their own share of moving pieces to the doctoral puzzle (Cumming 2010; Mantai 2015).

The multifaceted nature of doctoral studies has led to different approaches being introduced in the discussion on doctoral education. Current research is mainly focused on supervision (see Martinsuo and Turkulainen 2010; Parker-Jenkins 2018) and other forms of support mentoring (see Brill et al. 2014; Mantai and Dowling 2015) all the way to doctoral students' mental health (see Baik, Larcombe, and Brooker 2019; Levecque et al. 2017; Sverdlik et al. 2018) and even to the very concept of doctorateness (Trafford and Leshem 2009; Wellington 2013; Poole 2015). While all these studies have clear merits and benefits, these often overly-narrow single facets run the risk of obscuring the view on the mosaic reality in which $21^{\text {st }}$ century doctoral students work and live.

To address this glaring gap, this study re-theorises doctoral education in terms of time and space. As any mediated social action (Scollon and Scollon 2004), doing doctoral studies always takes place in specific spaces within and across specific timescales. These, in turn, have consequences and linkages to other spaces and timescales in society. To give the spatiotemporal dimension of doctoral education the visibility it deserves, I introduce a body of literature from sociolinguistics that can assist in theorising doctoral education further: the concept of scales (Blommaert 2007; Blommaert, Westinen, and Leppänen 2015) and the methodological approach of nexus analysis (Scollon and Scollon 2004; 2007). The first allows imagining social phenomena as something layered, rather than linear, allowing to add those missing dimensions of space and time into the discussion. The second provides a useful set of tools to study mediated social action by examining a versatile set of data, collected during a longer period of time. Furthermore, nexus analysis allows an analysis capable of 
addressing the facilitation of change; the ultimate goal of nexus analysis. This is important to note, as conducting nexus analysis rarely involves specific research questions but instead it is the research process and the resulting change and new questions that are "the answer" (Scollon \& Scollon 2004).

The data for this study was collected by doing insider ethnography at CERN (the European Organization for Nuclear Research), located on the border of Switzerland and France, for 18 months. As the participants were working with full-time funding and the stateof-the-art equipment, these settings provided an exceptional opportunity to focus on 'what is really going on' when the basic pieces of doctoral work — the resources - were already in place.

\section{'Doctoral enterprise', other holistic models, and what is missing}

Ten years ago, Cumming (2010) argued that, to meet the demands of the constantly evolving doctoral education, a more holistic model is needed. In the same work, he praiseworthily listed earlier models by Holdaway (1996), Thorlakson (2005), and McAlpine and Norton (2006). However, he criticised the assumption that doctoral education is something that only involves the student and their supervisor (see also Baker and Lattuca 2010; Baker Sweitzer 2009; Hopwood 2010). According to Cumming (2010), the previous approaches also treat doctoral education as something only happening within university walls, in a vacuum unaffected by external forces. To address these shortcomings, Cumming (2010) created a new holistic model of doctoral education by using Schatzki’s (2002) schema of piling-up activities, and Kemmis's (2005) conceptualisation of practice. In an effort to illuminate what so many others had missed, Cumming also asserted that doctoral students are in some ways 
independent, as are their supervisors but both are also part of specific socio-historical contexts.

Cumming's model of 'doctoral enterprise' (2010: 31) focuses on doctoral practices (curricular, pedagogical, research, and work); the central activities that doctoral students perform during their studies. In turn, doctoral arrangements surrounding these practices include components provided by three types of actors: participants, academy, and community. These arrangements illustrate how the relationships, networks, and resources of these three groups are linked with doctoral practices. Cumming argues that this model offers clear advantages over earlier attempts to provide new insights into doctoral studies, by for example analytically situating doctoral education within a complex ecosystem of interrelated components rather than as an oversimplified, linear system of inputs and outputs. It also treats doctoral education as a shared responsibility of the student and supervisor but also as a responsibility of other stakeholders within and outside academia, such as the state.

Despite of these undeniably important analytical insights, Cumming's model, as many other higher education studies, fails to address the spatiotemporal dimension of $21^{\text {st }}$ century academia (see also Shahjahan 2019). This continues the tradition of treating and examining doctoral education as something that happens over a few years' time within the walls of a single university. While Cumming (2010) implicitly touches on some spatiotemporal issues, such as 'historical developments' (31) and 'cultural understandings' (31) reflected within doctoral practices, they are not explicitly present in his model. Finally, although Cumming states that the nature of both doctoral practices and arrangement is 'multidimensional and interrelated' (34), the metaphors he uses are solely two-dimensional: doctoral arrangements are referred to as 'a rich tapestry of interwoven elements' (33) and doctoral work can be described as a 'doctoral interface' (26). In order to fundamentally advance thinking when it 
comes to the doctoral process, more dimensions are needed. This, I suggest, can be accomplished by Blommaert's $(2007 ; 2019)$ conceptualisation of scales.

\section{Scales as a vertical metaphor}

Scales, as conceptualised by Blommaert $(2007 ; 2019)$, is a vertical metaphor which allows the analyst to move beyond the limitations of two-dimensional thinking. The main purpose of this concept is to demonstrate that social phenomena are layered: of different order, hierarchically ranked, stratified, or power-invested. Blommaert (2007) argued that this layered nature of different phenomena is tied to differences between scales. To accompany and complement the existing horizontal and linear metaphors of 'distribution', 'spread', 'flow', and 'trajectory', scales can be used as an analytical metaphor which illuminates the nuances that are needed in studies examining globalisation (Blommaert 2007). I argue that multidimensional thinking is also needed to move beyond the limitations of most literature focused on doctoral education.

Blommaert (2007) exemplifies that in our everyday life, we constantly have to observe the norms that are attached to a multitude of authorities which can either be local/momentary or translocal/lasting; the family, a group of peers, religion, the media, transnational networks, the state, the labour market, role models, and so forth. Most of these can also be found in relation to doctoral education: these authorities can form a support network for the student (family and friends), they can limit the duration of studies (university or state), or even affect the initial choice of study (labour market demands). Furthermore, as Blommaert (2007) asserts, scales can be used to illustrate a layered continuum, where social events and processes move and develop: They have local (micro) and global (macro) dimensions as extremes, with several in-between states (e.g. the state). This is where the 
strength of scales lies: When studying social events or action, the concept refers to a layered and stratified model of society or a system as a frame for the interpretation of different types of current phenomena in communicative action. In this way, power and inequality become incorporated into our ways of imagining such phenomena: Rather than seeing them as 'exceptional aberrations in social life' (Blommaert 2007: 7), they can be seen as integral features of every social event. (Blommaert, Collins, and Slembrouck 2005; Blommaert 2007).

What does Blommaert mean by this? According to sociolinguistics, the reason context-dependant communicative acts are understood because they are coherent with previous traditions of making sense and connected to patterns of understanding. This type of duality is generally referred to as 'micro' and 'macro'. To explore the complexity between these extremes, and the transition from one level to another, different kind of theoretical tools have been created, such as Goffman's (1974) ‘frames' and Bourdieu’s (1990) 'habitus'. As Blommaert (2007) argued, these concepts examine the 'jump' from one scale to another. (Blommaert 2007; Blommaert, Westinen, and Leppänen 2015; Geertz 2004). Examples of such jumps are from momentary to timeless, from local/situated to translocal/widespread, from personal/individual to impersonal/collective, and from subjective to objective (Blommaert 2007).

In this article I will not focus on scale-jumps in individual situations and communicative acts, however, but instead focus on scales of different actions and actors. In other words, I do not use scales merely as a 'sociolinguistic concept ${ }^{\text {'1 }}$ but also as a general vertical metaphor that facilitates a multidimensional analysis of doctoral studies, spotlighting

\footnotetext{
${ }^{1}$ In his later work (Blommaert, Westinen, and Leppänen 2015), Blommaert admitted that he was not very happy with his original ideas of scale, presented in the 2007 paper. He went on to call it underdeveloped - "a clumsy and altogether unsuccessful attempt" (121). However, he did not give up on using the concept, and later refined it, drawing the concept fully into semiotics in the 2015 paper (ibid.). In his recent commentary (2019), Blommaert looks back at his extensive work, presenting what scales as a sociolinguistic concept has enabled him to do, and what it has not.
} 
issues that are ignored by the literature reviewed for this study. To do this, I suggest using nexus analysis as a mode of inquiry.

\section{Focus on mediated social action: Nexus analysis as a qualitative mode of inquiry}

In relation to scales, Blommaert, Westinen, and Leppänen (2015) concluded that when using several data sets and methods of analysis, it is possible to widen the range of the studied issue. To study a topic in such a way, nexus analysis (Scollon and Scollon 2004) offers a compelling approach from the field of sociolinguistics, and within ethnographic and discourse-analytical approaches in general (Hult 2015). Instead of language use only, it focuses on social action and those relationships that exist between different semiotic (meaning-making) resources and social issues (ibid.). For this reason, it is also an attractive mode of inquiry to advance the ideas about doctoral education.

The core concept of nexus analysis is social action. Scollon and Scollon (2004:11) define it as 'any action taken by an individual with reference to a social network'. When a specific social action happens repeatedly, it can be called a social practice. Social actions and practices are surrounded by three intertwined elements:

1) historical bodies (how a specific role is played by different people, depending on what their personal experience is; includes one's own goals and purposes as well as one's physical attributes),

2) discourses in place (all those discourses circulating a material place (and moment in time) where specific social action happens, relevant or irrelevant), and 
3) interaction orders (all those possible social arrangements that are used

to form relationships during social interaction; see also Goffman 1971, 1983).

Based on decades of previous work in higher education settings in Alaska, US, the Scollons specifically designed nexus analysis to explore different types of social phenomena as complex systems. The underlying idea is similar with the concept of scales: nexus analysis encourages the researcher to examine linkages between smaller and larger actions (or lower and higher scales). This is why the researcher should not 'get stuck' on single observable moments, events, or participants. (Scollon and Scollon 2004; Hult 2015, Pietikäinen et al. 2011). To guide a nexus analyst in their practical work, Scollons (2004) created a three-stage process: engaging, navigating, and changing the nexus of practice. To test the usefulness of nexus analysis for studying doctoral education, I went to CERN, one of the world's largest and best-known research centres, and applied the Scollons' approach.

\section{Data and methodology}

\section{Engaging: Doing insider ethnography at CERN}

The data for this study was gathered by doing insider ethnography (Aarnikoivu 2016; Alvesson 2003) at CERN (the European Organization for Nuclear Research) between July 2015 and December 2016. Founded in 1954 for the purposes of the European Council for Nuclear Research, the CERN laboratory is located on the border of France and Switzerland, next to Geneva. CERN's main focus is particle physics; to study the fundamental constituents of matter, as well as the forces that act between them. In 2019, CERN has around 20 different 
experiments working in its facilities. It directly employs about 2,500 people and has approximately 12,000 scientists of over 100 nationalities from over 70 countries affiliated with it. It should be noted that CERN does not grant any degrees: its doctoral students are socalled Associated Members of Personnel (i.e. not employed) and the validity of their contract of association is tied to being registered as a student at their home university during the entirety of the CERN contract. The funding usually comes from either the home institute (salary/grant) or from national scholarship programmes. In 2016, 318 people were selected to study at CERN's Technical or Doctoral Student Programme. (CERN 2019).

The basis for this study came to be during spring 2015 when I moved to the greater Geneva area. By joining the CERN board games club (which is also open for people outside CERN), I acquired an access card to CERN premises. By using snowball sampling, I located and recruited eight doctoral students to participate in this study. At the time of the data collection, the participants were 26 to 32 -year-old doctoral students of physics or engineering, who were at different stages of their studies (two at the beginning, three in the middle, three in the final stage). They came from eight different EU/EEA countries, where they had also completed their MSc degrees, except for one student who had moved to another country after completing their MSc. To ensure the anonymity of the participants, no further individual details on them will be provided. Each of the participants signed an informed consent participation form at the beginning of the study. In addition to this, I obtained a permission from a legal adviser from CERN's HR department, agreeing that CERN would only be used as a background information for the participants.

I began the data collection by conducting a semi-structured interview with each participant. In the interview, I asked about the participants' family and study background, why they decided to start university studies and eventually do a doctorate, how they started working at CERN, what they would like to do after completing the doctorate, about their 
daily work and work practices, their plans for the future, and their perceptions of their current life situation or circumstances outside work. This - arriving at CERN, finding the relevant social actors, and conducting the first interviews - forms the first stage of nexus analysis; engaging the nexus of practice.

\section{Navigating: zooming in and out to find out what is relevant}

After a few months, I gradually moved into the second stage of nexus analysis, navigating, where the main task is to analyse the three different aspects of social action listed previously; historical bodies, discourses in place, and interaction order. Furthermore, I looked for links and transformations between them (Scollon \& Scollon 2004) by observing the participants, talking to them during and outside their working hours, focusing on the topics that had emerged in the interviews. Over the course of fieldwork, some new themes and topics emerged, as the situation of the participants changed. All the notes were added to my fieldwork journal, which also included reflections regarding my own work. I also recorded two group meetings of one of the participants and took 360 photos in different parts of CERN. The data collected for this study is summarised in Table 1:

[Insert Table 1 here]

The analysis, which begins already at the navigating stage, was conducted and organised by creating two sets of nexus analytical questions. As a basis for both sets, I used the practical fieldguide for nexus analysis, provided as an appendix in the Scollons 2004 book Nexus Analysis. Discourse and the Emerging Internet. The sets were as follows: 
1) The set of nexus analytical questions used at the data collection stage (Appendix 1)

2) The set of nexus analytical questions used at the data analysis stage (Appendix 2)

The reason for two sets of questions is the evolving design of doing nexus analysis: instead of having a ready-made set of detailed research questions at the beginning of a research project, the nexus analyst is studying a social phenomenon or practice from a wider perspective (Set 1). This is why the data collection and the analysis have to be directed towards where the researcher finds any kind of reoccurring conflicts or contradictions between what is claimed is being happening or being done and what is actually happening or being done (Scollon \& Scollon 2004: 158). This I did throughout the navigation stage by what the Scollons (2004) call zooming in and zooming out. In this way, I did not 'get stuck' on specific moments, events, or participants but instead could shift my focus in case I found that what I had been observing so far did not seem to be relevant after all. For example, at the beginning of my data collection I assumed that all doctoral students have financial issues but, as it quickly turned out, these participants did not have any, which made me then zoom out, to find what my initial assumptions might have obscured.

While navigating the nexus of practice, it was striking how this group of extremely talented, bright, young researchers had a great deal to offer for their respective research communities and future knowledge production. Simultaneously, however, I observed how they were constantly confronting issues with various power-invested authorities, such as university or state. Thus, to focus specifically on the spatiotemporal dimension of doctoral education, I chose a more detailed set of analytical questions (Set 2) involving questions of space and time. The processes of continuously zooming in and out finally brought me to focus on the eye-catching tension involved in how different spaces, timescales, and the 
authorities related to them enable but also regulate, and —in some cases_-restrict social action. The results of this many-step analysis will be presented next.

\section{Results}

Based on the analysis I first identified the relevant spaces and timescales that were circulating the studied nexus of practice. These are listed below in Table 2:

[Insert Table 2 here]

By examining Table 2, it can be noticed that spaces (where socially mediated action entailed in doctoral studies happens) tremendously vary in terms of their horizontal size. However, these spaces also include vertical dimensions linked to hierarchy and power (Blommaert 2007). The same applies to timescales: they can be placed linearly on a timeline (horizontally) or they can be viewed as shorter and longer timescales (vertically), each of which are related to an authority with power, such as the university or the state, which set the framework for the duration of studies, for example.

To illustrate this, compare the use of the country name as well as the time period in these two following cases during the same interview:

1. I still have two more years but my plan actually is not to back to [the capital], I would like to go back to [country], but the western part.

2. No I did my master's degree in seven years because in [country] we don't have restrictions on this. 
In the first example the participant is talking about their country of origin as a horizontal space; an area where they would like to move back to after finishing their degree. However, in the second one the country name bears an additional meaning. It refers to power; the laws, regulations, or cultural norms of that country. Additionally, in both sentences the number of years refers to a timescale determined by "the country". In the first example the time is limited, whereas in the latter it is not.

As the above excerpt also illustrates, doctoral students have to acknowledge and follow several different norms attached to these spaces to carry out their studies and daily work duties. These norms might either be local (lower scale), translocal (higher scale), or something in between. In terms of horizontal size, for example, the smallest spaces that I observed were those of daily work (on related activities, see Jazvac-Martek, Chen, and McAlpine 2011), thus also making them the most common spaces of doctoral studies: offices, experiment halls, meeting rooms, and cafeterias, all playing a central role in the participants' everyday lives. Here, one of the participants describes their typical work day:

\footnotetext{
"On a normal day I go to work about at nine, spend the next half an hour at coffee, I don't drink coffee but coffee is an event which happens at work so... So that's a good half hour and lunch at 12 *laughs*, then there's another coffee at about two o'clock, between that it's just working, either in the experiment zone, just working on hardware or programming or designing things and software."
}

Although the participant was describing their day with a humorous tone, it illustrates how specific, scheduled events at CERN (such as the lunch) provide a framework for daily activities, such as programming and designing software. These activities take place in 
facilities which enable doctoral students to carry out their research effectively, and to work in highly international research groups and settings for several years. This ultimately leads (or successfully led) to them obtaining a doctorate.

While these spaces enable social action, they also regulate or restrict it, however. For instance, these same spaces involve rules that the participants had to follow: the rules of a research group, an experiment hall, or CERN, meaning that the participants were subjected to several different authorities at once. The following excerpt is from my fieldnotes regarding a doctoral student, who was planning to attend an international physics conference and present their results there:

[The doctoral student] got accepted to [the conference] to present his results, which are now almost ready. They first need to have them accepted by the collaboration. They present their results next Monday, which is a rehearsal, and then there's the actual talk on Tuesday. After this they will still have the chance to make modifications. The results will finally be approved or rejected two weeks before the conference. [August $25^{\text {th }}$ ]

Although in the end the results were accepted and the doctoral student attended the conference, it was a process involving several different authorities, which functioned as a gatekeeper for this particular event and action: attending an academic conference. Such a process was not rare: To be allowed to perform particular actions in experiment halls, the participants had to complete a specific training course (such as a harness training, confined spaces training, or fire training). The restrictions also concerned an actual, physical access, as the CERN sites are not open to anyone. One has to have an access card to enter, for which one needs to fill in several forms and visit two different offices, which both had differing and limited opening hours. 
The second regulating (or restricting) factor was related to longer timescales impacting the participants' studies and life: Although most of the participants had a short or medium-term action plan, as well as guaranteed funding, it was equally clear that 'life after PhD' was a mystery to all of them. Previous research has already shown the complex relationship between mobility and career advancement, especially for those with a partner and/or children (see e.g. Oliver 2012). Decisions regarding mobility are not one-time events but rather an ongoing process, where one has to constantly negotiate with family members (Ackers and Stalford 2007). Here, the spatial (where to live?) and temporal (in one year/five years/ten years) dimensions also come together to form a highly complex nexus, bringing two more authorities for doctoral students into view: the family and the labour market. However, for the participants of this study there was an additional group: friends. As one participant reflected their current, mobile situation and the future:

\footnotetext{
I don't want to live abroad for many years. I want to have a place where I can make friends that will stay there, rather than go somewhere and make a lot of $\mathrm{PhD}$ friends, who five years later will all be in different places. I want to have a games club where I can get to know some people and they can invite me to dinner and if I go abroad for a semester and come back, they're still there.
}

The excerpt suggests that perhaps there are other matters besides career, a steady income, and family that bear an importance for doctoral students when they make their plans for postdoctoral life.

The final regulating factor was also connected to a high spatial scale-level: the state. It was not unusual that a participant was born in one country, doing their doctorate in second (as an international student), lived in third (usually France), and worked in fourth (Switzerland). Most participants crossed the border of France and Switzerland twice a day, 
sometimes more often. The frustration caused by the practicalities related to expatriate life is well illustrated by the following excerpt:

\footnotetext{
“[In France] you need an address to open up a bank account but you need a bank account to have an address, so stuff like that. There are so many steps in renting a house. You need to get an insurance for that house, for which you need a French bank account. Electricity and water can only be paid from a French bank account so you need that but to open a bank account you need a valid address because all the mail will go to that address you provide there so... [... and] I wanted to get a health insurance, which is paying a lot of thousands of euros over this period, so I thought they would be interested in having me. But speaking another language, the phone conversation failed miserably. In the end we realised we don't understand each other."
}

In the excerpt, the participant lists a number of practical challenges: where and how to find housing, how open a bank account, pay electricity and water bills, acquire a health insurance, and in which language(s) to do all this. Although many participants spoke a little bit of French when arriving in the area, it was usually not enough to discuss issues more complex than what to order at a restaurant. Using English during official encounters was sometimes an alternative, but more often it was not, adding additional obstacles for the participants to cross in their every-day encounters.

\section{Discussion: Changing the nexus of practice}

As identified in the analysis, most of the social action involved in doctoral studies is happening in small (or local) spaces, meaning that they are of lower scale: they are 
momentary (last for a brief period of time) and individual (each participant is doing a specific task assigned to them). However, the action itself is regulated by authorities (higher scales), such as different research groups and university departments, which are impersonal and collective agents. As an additional authority for doctoral students each had their respective universities and funding agencies that regulated the completion of their degree: Each institution has their own (general, objective and uniform) regulations, according to which doctoral studies have to be carried out. These regulations, in turn, might be a result of specific national-level laws, scales that could be considered as being 'in-between': not fully local (within a department or a university) but not fully translocal (extending beyond national borders) either.

What nexus analysis allows to do is to shift the attention from these specific authorities towards the tension between the different scale-levels they operate at: Regulations that are formulated on a high scale level (such as national legislation) apply to everyone within one country or area largely ignore the individual needs or motivations. This can place doctoral students (or any persons) experiencing complex mobilities (Aarnikoivu et al. 2019; Archer 1995; Urry 2007) or hypermobility (Courtois 2020) into a challenging situation: While they all have their own individual reasons and motivations to pursue doing a doctorate at CERN, or abroad in general, they are also part of a power-invested system and discourses on the internationalisation goals of European universities, European Commission, and regional and national policies. While these policy goals are uncritically profiled as highly important, they might not be viewed as positively by an internationalising individual trying to fill in a French tax form for the first time in their life.

As discussed earlier in this article, holistic models on doctoral education (e.g. Cumming 2010; Holdaway 1996; McAlpine and Norton 2006; Thorlakson 2005) have treated doctoral education in a two-dimensional way; focusing largely on what happens during 
doctoral studies. It has now been ten years since the model by Cumming (2010) and research on doctoral education is thriving. Simultaneously, however, doctoral students' mental health issues are increasing (Barry 2018; Woolston 2017, 2019). This raises two questions: What are we currently missing? Are we asking the right questions in the first place? Incidentally, these are the same questions that inspired the Scollons to create the nexus analytical framework was conducted, in part, at the University of Alaska already 40 years ago. What connects that moment in time to the present day is the imperative of change, seen by activist scholars such as the Scollons, Blommaert, or Kemmis, concerning topics that matter. Following the two stages of engaging and navigating the nexus of practice, the final stage of nexus analysis is changing it. Scollon and Scollon (2004) asserted change as the goal, from the outset, as they crafted nexus analysis. Conducting nexus analysis is not supposed to have a positivist solution bur rather find and ask new, better questions for future course of research, practice, and policy-making.

Based on the analysis, I present the following set of questions that will guide my subsequent actions, as an analyst, as I move forward in the development of my evolving approach to doctoral studies:

1. Physical and vertical spaces: Could universities provide even more flexible ways of studying and working, independent of place and/or time? Which authorities are enabling/regulating/restricting (mobile) doctoral education?

2. Complex mobilities: Do personnel in higher education institutions across Europe have the sufficient skills and knowledge to provide assistance for their students experiencing complex (or any type of) mobilities? If not, could the situation be improved? 
3. Future: Could the individual needs of mobile doctoral students (i.e. future workforce), the needs of their families, and the shared needs of European knowledge economies be better articulated? Do doctoral students have to "accept future uncertainty", or can it be reduced by changes in practices and policies regarding the challenges this analysis spotlights?

4. Questions regarding the use of nexus analysis: Could scales and nexus analysis, used here in a STEM context, uncover equally interesting findings in other types of settings? If nexus analysis crosses state-of-the-art on the topic of doctoral education, does it have similar potential on other, equally well-beaten paths?

Asking questions alone does not cause change, however. I also do not argue that studies focused on individual phenomena, such as supervision, writing, or mental health should be completely discarded. Rather, I am arguing that in order to facilitate change, narrow questions, focal points, or levels of analysis are not enough. Moreover, it ought to be acknowledged that a single study is not enough to address the various challenges pointed out in the analysis - this would be too heavy a burden for any study. However, what a single study such as this one can do is to open up a discussion on how social action-such as doing doctoral studies_could be approached.

\section{Conclusion}

Although the data collection for this study ended already at the end of 2016, afterwards I have seen almost all of the participants graduate and find their place in the job market, either in academia or in industry. Even those who have not yet graduated are well on their way doing so. Some of the participants have left CERN with their doctorates while some of them 
are still there. But even though these doctoral students' stories have perhaps been more positive than they expected back in 2016 , their anxieties and uncertainties should not be discarded as something that "will eventually pass", because they might not, which again might have severe consequences as shown by the recent literature on doctoral students' mental health (see Levecque et al. 2017).

In this article, I have shown how the spatiotemporal dimension of doctoral education can be studied by utilising Blommaert's conceptualization of scales, within the mode of inquiry of nexus analysis. The analysis shows that doctoral students act — and are acted on within multiple horizontal but also vertical spaces, which all have an effect on shorter but also much longer timescales. This viewpoint connects the existing literature on doctoral education and the individual issues it raises to a wider, more structural context, where European doctoral education takes place. This is something that has been missed in the general approach that has been taken to doctoral studies, especially during recent decades, as shown in the literature review.

If done well, inductive and holistic approaches allow the analyst to better tap into the complexity that is subjectively experienced by participants. At the same time, they offer more convincing accounts of the cultural and structural dynamics, which are not necessarily understood by the participants or any other actor within the scope of analysis. For this, nexus analysis has proven to be an excellent mode of inquiry: By combining different theoretical concepts (scales; social action; social practice) with different methodologies (insider ethnography; discourse analysis), it has allowed me to go beyond the individual facets of doctoral education — the typical targets of research — and to examine the bigger picture in a unique way. Finally, it has enabled me to form critical questions concerning the studied topic but also the mode of inquiry itself. 
As Blommaert (2007:7) stated, power is incorporated in our ways of imagining different phenomena. Doctoral education is no exception. Doctoral students, even those conducting their studies in "dream-come-true settings", such as CERN, are still part of different layered, power-invested systems. In this way, they are no different from doctoral students who are doing their research "within four university walls" and who are also involved with a number of different authorities, such as the university and the state — or, for international doctoral students, two or more states. Therefore, equally important to the central findings of this study are its implications: in many cases, the European Commission, national states, higher education institutions, and doctoral programmes have only scratched the surface where actors profile doctoral education geared towards $21^{\text {st }}$ century knowledge work. As Favell and colleagues (2007) have argued, highly-skilled (OECD 2008), mobile workforce, such as the participants of this study, are valuable for knowledge production and transfer, as well as for economic productivity of a country. We might not be able to predict to which country every person ends up moving after completing a doctorate. That said, whichever country it is, we ought to act on power-laden boundaries that currently make knowledge production far more convoluted and complicated than it needs to be.

\section{Acknowledgements}

This work was supported by the Emil Aaltonen Foundation under Grants 170007 N1 and 180007 N1; Ellen and Artturi Nyyssönen Foundation [no grant number available]; and the Centre for Applied Language Studies [no grant number available].

\section{Disclosure of interest}

No potential conflict of interest was reported by the author. 


\section{References}

Aarnikoivu, M. 2016. “'Not in my backyard but in my front room’: A review of insider ethnography." Tiedepolitiikka 41 (3): 47-56.

Aarnikoivu, M., S. Korhonen, D. Habti, and D. M. Hoffman. 2019. "Explaining the Difference between Policy-Based Evidence and Evidence-Based Policy: A Nexus Analysis Approach to Mobilities and Migration.” Journal of Finnish Studies. Special Issue: Engaging the New Mobilities Paradigm in the Context of Finland 22 (1\&2): $213-240$.

Ackers, H.L., and Stalford, H. 2007. "Managing Multiple Life Courses: The Influence of Children on Migration Processes in the European Union,”. In Social Policy Review: Analysis and Debate in Social Policy 19, edited by K. Clarke, T. Maltby, P. Kennet, 317-339P. Bristol: Policy Press.

Alvesson, M. 2003. "Methodology for close up studies - struggling with closeness and Closure." Higher Education 46 (2): 167-93.

Archer, M. 1995. Realist Social Theory: The Morphogenetic Approach. Cambridge: Cambridge University Press.

Baik, C., W. Larcombe, and A. Brooker. 2019. "How universities can enhance student mental wellbeing: the student perspective." Higher Education Research \& Development 38 (4): 674-687. doi:10.1080/07294360.2019.1576596.

Baker, V. L. and L. R. Lattuca. 2010. "Developmental networks and learning: toward an interdisciplinary perspective on identity development during doctoral study." Studies in Higher Education 35 (7): 807-27.

Baker Sweitzer, V.B. 2009. "Towards a theory of doctoral student professional identity 
development: A developmental networks approach." Journal of Higher Education 80 (1): $1-33$.

Barry, K. M., Woods, M., Warnecke, E., Stirling, C., \& Martin, A. 2018. "Psychological health of doctoral candidates, study-related challenges and perceived performance." Higher Education Research \& Development 37 (3), 468-483.

Blommaert, J. 2005. Discourse: A critical introduction. Cambridge, UK: Cambridge University Press.

Blommaert, J. 2007. "Sociolinguistic scales.” Intercultural Pragmatics 4 (1): 1-19.

Blommaert, J. 2019. "Sociolinguistic scales in retrospect". Tilburg Papers in Cultural Studies 225.

Blommaert, J., J. Collins, and S. Slembrouck 2005. "Spaces of multilingualism." Language \& Communication 25: 197-216.

Blommaert, J., E. Westinen, and S. Leppänen. 2015. "Further notes on sociolinguistic scales." Tilburg Papers in Culture Studies 89: 1-11.

Bourdieu, P. 1990. The Logic of Practice. Cambridge: Polity.

Brill, J. L., K. K. Balcanoff, D. Land, M. Gogarty, and F. Turner. 2014. "Best practices in doctoral retention: Mentoring." Higher Learning Research Communications 4 (2): 26- 37. http://dx.doi.org.10.18870/hlrc.v2i2.66

CERN. 2019. About CERN. http://home.cern/about. Accessed on June 26th, 2019.

Courtois, A. 2020. "Study abroad as governmentality: the construction of hypermobile subjectivities in higher education”. Journal of Education Policy 35 (2), $237-257$.

Cumming, J. 2010. "Doctoral enterprise: a holistic conception of evolving practises and arrangements." Studies in Higher Education 35 (1): 25-39.

Favell, A., M. Feldblum, and M. P. Smith. 2007. "The Human Face of Global 
Mobility: A Research Agenda." Transaction Social Science and Modern Society 44 (2): $15-25$.

Gardner, S. K., and Gopaul, B. 2012. "The Part-Time Doctoral Student Experience”. International Journal of Doctoral Studies 7: 63-78. https://doi.org/10.28945/1561

Geertz, C. 2004. "What is a state if it is not a sovereign? Reflections on politics in complicated places." Current Anthropology 45 (5): 577-593.

Goffman, E. 1971. Relations in Public. London: Allen Lane.

Goffman, E. 1974. Frame Analysis: An Essay on the Organization of Experience. New York: Harper \& Row.

Hakala, J. 2009. "Socialization of Junior Researchers in New Academic Research Environments: Two Case Studies From Finland.” Studies in Higher Education 34 (5): $501-516$

Holdaway, E.A. 1996. “Current issues in graduate education.” Journal of Higher Education Policy and Management 18 (1): 59-74.

Hopwood, N. 2010. "A sociocultural view of doctoral students' relationships and agency." Studies in Continuing Education 32 (2): 103-117.

Hult, F. M. 2015. "Making Policy Connections across Scales using Nexus Analysis”. In Research Methods in Language Policy and Planning: A Practical Guide, edited by F. M. Hult and D. C. Johnson, 217-231. Wiley-Blackwell.

Jazvac-Martek, M., S. Chen, and L. McAlpine. 2011. "Tracking the doctoral student experience over time: cultivating agency in diverse space”. In Doctoral Education: Research Based Strategies for Doctoral Students, Supervisors and Administrators, edited by L. McAlpine and C. Amundsen, 17-36. New York: Springer.

Kemmis, S. 2005. "Knowing practice: Searching for saliences.” Pedagogy, Culture and Society 13 (3): 391-426. 
Koole, M. and S. Stack. 2016. 'Doctoral students' identity positioning in networked learning environments." Distance Education 37 (1): 41-59. doi:10.1080/01587919.2016.1153961.

Levecque, K., F. Anseel, A. De Beuckelaer, J. Van der Heyden, and L. Gisle. 2017. "Work organization and mental health problems in PhD students." Research Policy 46 (4): 868-879.

Mantai, L. 2015. "Feeling like a researcher: experiences of early doctoral students in Australia." Studies in Higher Education 42 (4): 636-50.

Mantai, L., and R. Dowling. 2015. "Supporting the PhD journey: insights from Acknowledgements." International Journal for Researcher Development 6 (2): 10621.

Martinsuo, M., and V. Turkulainen. 2011. "Personal commitment, support and progress in doctoral studies." Studies in Higher Education 36 (1): 103-20.

McAlpine, L., and J. Norton. 2006. "Reframing our approach to doctoral programs: An integrative framework for action and research.” Higher Education Research and Development 25 (1): 3-17.

Nasiri, F., and F. Mafakheri. 2015. "Postgraduate Research Supervision at a Distance: A Review of Challenges and Strategies.” Studies in Higher Education 40 (10): 1962 1969.

OECD. 2008. The Global Competition for Talent: Mobility of the Highly Skilled. Paris: Organization for Economic Cooperation and Development.

Oliver, E. A. 2012. “Living Flexibly? How Europe’s Science Researchers Manage Mobility, Fixed-Term Employment and Life Outside of Work.” International Journal of Human Resource Management 23 (18): 3856-71.

Parker-Jenkins, M. 2018. "Mind the gap: developing the roles, expectations and boundaries in 
the doctoral supervisor-supervisee relationship." Studies in Higher Education 43 (1): 57-71. doi:10.1080/03075079.2016.1153622.

Pietikäinen, S., P. Lane, H. Salo, and S. Laihiala-Kankainen. 2011. "Frozen actions in the Arctic linguistic landscape: a nexus analysis of language processes in visual Space.” International Journal of Multilingualism 8 (4): 277-98.

Poole, B. 2015. "The rather elusive concept of 'doctorateness': a reaction to Wellington." Studies in Higher Education 40 (9): 1507-22. doi:10.1080/03075079.2013.873026.

Schatzki, T. R. 2002. The site of the social. University Park, PA: Pennsylvania State University Press.

Scollon, R. and S. W. Scollon. 2004. Nexus Analysis: Discourse and the emerging internet. London, UK: Routledge.

Scollon, R. and S. W. Scollon. 2007. "Nexus analysis: Refocusing ethnography on action." Journal of Sociolinguistics 11 (5): 608-25.

Shahjahan, R. 2019. "On 'being for others': time and shame in the neoliberal academy". Journal of Education Policy. https://doi.org/10.1080/02680939.2019.1629027

Sverdlik, A., N. C. Hall, L. McAlpine, and K. Hubbard. 2018. "The PhD Experience: A review of the factors influencing doctoral students' completion, achievement, and well-being.” International Journal of Doctoral Studies 13.

Thorlakson, I. 2005. "Models of doctoral training in European political science." European Consortium for Political Research 4 (1): 82-94.

Trafford, V., and S. Leshem. 2009. "Doctorateness as a threshold concept." Innovations in Education and Teaching International 46 (3): 305-16.

Urry, John. 2007. Mobilities. Cambridge: Polity Press.

Waaijer, C. J. F., R. Belder, H. Sonneveld, C. A. Van Bochove, and I. C. M. van der Weijden. 
2017. "Temporary Contracts: Effect on Job Satisfaction and Personal Lives of Recent PhD Graduates." Higher Education 74 (2): 321-339.

Verso.

Wellington, J. 2013. “Searching for 'doctorateness'.” Studies in Higher Education 38 (10): 1490-1503. doi:10.1080/03075079.2011.634901.

Woolston, C. 2017. “Graduate survey: A love-hurt relationship”. Nature 550 (7677), 549552.

Woolston, C. 2019. "PhDs: The tortuous truth". Nature 575 (7782), 403-406.

\section{Appendices}

Appendix 1: The set of analytical questions used at the data collection stage (formed on the basis of A Practical fieldguide for nexus analysis [Scollon \& Scollon, 2004, 152-178]).

1. How habitual or innovative is the action-practice for that person? That is, to what extent is this a 'practice'?

2. How intentional (agentive) or accidental? How do you know? According to whom is this intentional?

3. When and where is the last prior 'like' action? That is, is there a link between this action and this type of place or these other participants?

4. To what other practices is this linked for this person? Does he or she always do something else at the same time? 
5. How much is this action keyed to the uniqueness of the person, or, alternatively, how dispensable is the person? Could it be anybody who does the action, just so long as it gets done?

6. What is the emotional valence or the emotional impact on the participant of this action? Is it exciting, routine, or boring to do this; is the action sought or avoided? Is it so much part of the historical body that the person sometimes wonders why it isn't as enjoyable as it used to be or as anticipated?

7. What discourses are transformed, resemiotised or internalised in this action?

8. What 'place' supports are available for this action such as furniture of particular kinds or the ambience or lack of it?

9. Is this a customary or unusual place for this action?

10. What kinds of over discourse are present?

11. Are any of the participants calling attention to objects or structures so that they can be talked about?

12. Overall how 'automatic' are the actions here?

13. Conversely, how new or unpractised are the actions you are studying?

14. If the action is new or unpractised, are there anticipations of future arcs of the cycle where this action is expected to become practice?

15. What conceptual tools are used (language, semiotic codes, number systems)?

16. How widely are these shared among the participants? How long or fully internalised are these concepts? Where, when, or with whom were these concepts internalised?

17. How is this action anticipated in the historical body of the persons involved?

18. Or was this action anticipated much earlier such as in taking a training course?

19. How often does this action occur in the life cycle of this person, or mediational means, or discourses? Is it very frequent, very rare? 
20. What are the immediately preceding and following intervals like or is this action a point in a tight series of actions?

21. Is this place a place of action or a 'quiet' place where little is expected to happen?

22. What are the big ' $\mathrm{D}$ ' discourses present in this discourse? How are those discourses 'present' as overt and how are they submerged?

23. What languages are used in taking an action; are they the same or different from the language of the analysis; does that make a difference in the templates being developed to analyse the action?

24. What power is implied in some participants (like the analyst) keeping notes and making recordings?

25. What hidden discourses are there? That is, what's not being said, being evaded, or so obvious that it's virtually invisible but nevertheless governing the entire action or activity?

26. How are the participants in the nexus analysis positioned in respect to the analyst conducting the discourse analysis?

Appendix 2: The set of analytical questions used at the data analysis stage (formed on the basis of A Practical fieldguide for nexus analysis [Scollon \& Scollon, 2004, 152-178]).

1. What are the typical spaces and timescales for the people, discourse, places, and mediational means that are crucial to the action you are studying?

2. How are these spaces and timescales constructed discursively and by whom?

3. How much agreement is there about these constructions?

4. In which spaces and where in the cycle does this action occur?

5. What relationships or linkages are there among or across spaces or timescales? 
6. Do some of these elements (or all of them) seem completely inevitable or completely accidental? Why are the inevitable ones so linked to this action?

7. Are two practices always linked or only accidentally or sporadically?

8. Do all participants see these linkages the same way?

9. Are some links incommensurable? That is, are there prohibited or impossible elements or linkages?

10. What anticipations on the part of which key social actors lead up to this action?

11. To what extent is the action embedded in the historical body in different ways for the participants involved?

12. Is the action limited in some way by the circumferences set by participants, discourses, objects, places, time etc.?

13. Do all participants agree on the most relevant spaces, timescale or circumstance?

14. How do the participants talk about why they have come to take this action?

15. Of what history do they see it as the outcome; what future is it projected toward?

\section{Tables}

Table 1. Data summary.

\begin{tabular}{|l|l|}
\hline Main data & $\begin{array}{l}7 \text { audio-recorded interviews (length varying between } 25 \\
\text { minutes and } 1 \text { hour } 20 \text { minutes, } 359 \text { in total) and } 1 \text { written } \\
\text { interview }\end{array}$ \\
\cline { 2 - 3 } & $\begin{array}{l}2 \text { audio recordings from a group meeting of } 1 \text { participant (29 } \\
\text { and } 69 \text { minutes) }\end{array}$ \\
\cline { 2 - 3 } & $\begin{array}{l}\text { Fieldwork journal consisting of } 74 \text { entries between } 19^{\text {th }} \text { of July, } \\
2015 \text { and January } 12^{\text {th }}, 2017 \text { and including: }\end{array}$ \\
\hline
\end{tabular}




\begin{tabular}{|l|l|}
\hline 1) notes on follow-up interviews, \\
2) notes on informal discussions with the participants, \\
3) fieldnotes written during and outside participants' \\
working hours on their life and work and life at CERN in \\
general, and \\
4) reflections on my own work. \\
$\begin{array}{l}360 \text { photos. To ensure the anonymity of the participants, these } \\
\text { photos are not used for analysis purposes. I took them during } \\
\text { my field work, in case I would not be able to go back to CERN } \\
\text { after finishing the data collection. However, this turned out not } \\
\text { to be the case, as I have been able to return to CERN after the } \\
\text { data collection as well. }\end{array}$ \\
\hline
\end{tabular}

Table 2. Identified spaces and timescales of CERN doctoral students.

\begin{tabular}{|l|l|}
\hline Spaces & Timescales \\
\hline experiment halls/offices, meeting rooms, CERN, & thesis writing, the annual CERN schedule, \\
conference venues, primary/secondary school, & completing primary/secondary school, completing a \\
university, different cities, different countries, & university degree, having an employment contract/a \\
Europe, wider than Europe, and outside work. & grant, and future/life after $\mathrm{PhD}$. \\
\hline
\end{tabular}

